\title{
RESULTS OF A RANDOMIZED TRIAL OF PARTNER NOTIFICATION IN CASES OF HIV INFECTION IN NORTH CAROLINA
}

\author{
Suzanne E. Landis, M.D., M.P.H., Victor J. Schoenbach, Ph.D., David J. Weber, M.D., M.P.H., \\ Manjoo Mittal, Ph.D., Baldev Krishan, M.A., Karen Lewis, B.S.P.H., and Gary G. Kogh, Ph.D.
}

\begin{abstract}
Background. We sought to compare two methods of notifying sex partners of subjects infected with the human immunodeficiency virus (HIV) or persons who had shared needles with them (needle-sharing partners): "patient referral," in which the responsibility for notifying partners was left to the patient, and "provider referral," in which providers attempted to notify partners.

Methods. Names of sex partners and needle-sharing partners and information on how to locate them were obtained from consenting HIV-infected subjects identified in the HIV-testing programs at three public health departments in North Carolina. The subjects were randomly assigned to a patient-referral group (in which patients had the initial responsibility for notifying their partners) or a provider-referral group (in which the study counselor notified the partners). The success of attempts to notify partners was monitored by means of interviews with counselors conducted both in the field and at the health department.
\end{abstract}

Results. Of $534 \mathrm{HIV}$-positive persons identified at the health departments, 247 (46 percent) did not return for counseling after the test, 8 were counseled outside the study, and 117 (22 percent) were ineligible. Of the 162 invited to participate, 88 (54 percent) declined and 74 (46

$\mathrm{A}^{\mathrm{L}}$ MOST all states have developed policies for the notification of sex partners of persons infected with the human immunodeficiency virus (HIV) and persons who share needles with them (needlesharing partners), in order to target counseling, riskreduction efforts, and medical and support services to those at high risk of being or becoming infected. ${ }^{1,2}$ An integral part of programs to control sexually transmitted diseases since the mid-1940s, ${ }^{3,4}$ partner notification is accomplished in two ways: by patient referral, also known as self-referral, and provider referral, formerly known as contact tracing. ${ }^{5-9}$ With the patientreferral method, infected persons ("index patients") are asked to notify their partners of the risk of infection and refer them to the health department for counseling and evaluation. When provider referral is used, trained public health counselors on the staff of the health department locate partners on the basis of the names, descriptions, and addresses provided by the patient, who may also notify partners, and tell them of their risk of infection. During the notifica-

From the Department of Epidemiology (S.E.L., V.J.S., D.J.W., M.M. B.K.) and the Department of Biostatistics (K.L., G.G.K.), School of Public Health, and the Department of Medicine, School of Medicine (S.E.L., D.J.W.), University of North Carolina, Chapel Hill. Address reprint requests to Dr. Landis at Mountain Area Health Education Center, 501 Biltmore Ave., Asheville, NC 28801

Supported through a cooperative agreement (5 U01 Al25868) with the National Institute of Allergy and Infectious Diseases.

Presented at the 118th annual meeting of the American Public Health Association, New York, October 1990, and at the annual meeting of the Robert Wood Johnson Clinical Scholars Program, Fort Lauderdale, Fla., November 5, 1990. percent) agreed. The subjects were mostly male (69 percent), black ( 87 percent), homosexual or bisexual ( 76 percent of the men), and had a median age of 30 years. Thirty-nine were assigned to the provider-referral group and 35 to the patient-referral group. In the provider-referral group 78 of 157 partners (50 percent) were successfully notified, whereas in the patient-referral group only 10 of 153 (7 percent) were notified. Of the partners notified by the counselors, 94 percent were not aware that they had been exposed to HIV. Overall, 23 percent of the partners notified and tested were HIV-positive.

Conclusions. In this trial, leaving the notification of partners up to the subjects (patient referral) was quite ineffective, despite the North Carolina law requiring that partners be notified. Partner notification by public health counselors (provider referral) was significantly more effective. Although the effectiveness of notification procedures is constrained by the accuracy of the information provided by HIV-infected patients, counselors who notify the partners of an infected patient can refer them to educational, medical, and support services targeted to persons at high risk for HIV infection and may encourage the adoption of less-risky behavior. (N Engl J Med 1992; 326:101-6.)

tion process, counselors always preserve the anonymity of the index patient. Intensive provider referral has reduced the number of cases of gonorrhea and syphilis, as compared with the numbers anticipated, and has helped to control outbreaks of these diseases. ${ }^{10-14}$

There are several problems involved in using provider referral for conventional sexually transmitted diseases, including difficulty in locating partners on the basis of information provided by index patients; high costs, resulting primarily from the frequently intensive efforts to locate partners; and concern about confidentiality and protection against discrimination on the part of both index patients and their partners. When provider referral is used in cases of HIV infection, additional problems are the lack of pharmacotherapy to cure the infection or to prevent transmission; the varying and limited success of counseling about changes in behavior; the difficulty patients often have in recalling the names of partners and in locating them because of the long incubation period for HIV; and heightened concern about confidentiality and social stigmatization..$^{15-19}$

Overall, although the potential benefits may outweigh the problems, the efficacy of provider-referral programs for HIV infection - to which, along with programs for HIV counseling and testing, the federal government allocated $\$ 86$ million in fiscal 1989 has not been adequately established. ${ }^{20}$ The available studies of provider referral in cases of HIV infection focus on descriptions of partner-notification pro- 
grams, provide information only about index patients and partners who use provider-referral services, and lack comparable information about partners when the index patient has the responsibility for notification (as in our patient-referral group). ${ }^{9,20-26}$ Studies in which index patients choose between provider referral and patient referral may suffer from selection bias, since the patients who select provider referral over patient referral may have characteristics that adversely affect their ability to locate or communicate with their partners.

In this report we present the results of a randomized trial of partner notification in cases of HIV infection. Specifically, we address the question, Does the provision of provider-referral services significantly increase the level of notification and testing of partners at high risk for HIV infection, as compared with the patient-referral method?

\section{MethodS}

\section{Setting}

This study was conducted at three large county health departments in North Carolina, a primarily rural state with 1925 reported cases of AIDS through July 1991 and an annual rate of 6.5 per 100,000 population from August 1990 through July 1991 - less than half the national rate. ${ }^{27}$ At the beginning of the study, only anonymous HIV testing (i.e., with patients identified only by number) was available at two of the health departments. Within eight months, all three health departments had added confidential HIV testing (with patients identified by name) through the clinics for sexually transmitted diseases, family planning, and tuberculosis.

\section{Subjects}

The study subjects were recruited from among clients with HIV infection confirmed by Western blotting who were identified through the counseling and testing programs (anonymous testing) and other health department clinics (confidential testing). HIVpositive clients who did not return for their test results and could not be located by the public health counselors were obviously not available for the study. Subjects were regarded as ineligible if they had previously tested positive for HIV and had no new sex or needlesharing partners (both hereafter referred to as "partners") $(n=22)$, had only partners whose names they did not know $(n=8)$, had had no sex or needle-sharing partners in the past year $(n=62)$, or lived outside the jurisdictions of the three county health departments or had only partners who lived outside them $(n=25)$.

\section{Recruitment}

After a preliminary test of study procedures and data-collection methods, subjects were recruited for the study from November 16, 1988, through June 30, 1990. HIV-infected persons returning for their test results were assigned to the public health counselors participating in the study. These counselors informed the patients of their HIV test results, provided standard counseling, and explained the study. After obtaining informed consent from those who wished to participate, the counselors collected the names of partners, information about how to locate them, and information on the type of sexual or needle-sharing activity engaged in, starting with the most recent partner and systematically going back one year. The subject was then randomly assigned to either the provider-referral group or the patient-referral group. Eligible subjects who declined to enter the study were given the North Carolina partner-notification form and encouraged to call the state program in Raleigh for help in notifying their partners. All names were made available only to the counselors and were destroyed after three months. The study was approved by the Committee on the Protection of the Rights of Human Subjects of the University of North Carolina School of Medicine.

\section{Procedure for Notifying Partners}

In the provider-referral group, subjects could choose to notify some or all of their partners themselves. The public health counselor immediately attempted to notify the remaining partners, if any, as well as all other partners who had not appeared at the health department within two weeks of an index patient's enrollment. The methods used were similar to those used in cases of syphilis, with the exception that HIV exposure was initially discussed in person rather than by mail or telephone. Colored cards with identification codes were provided to subjects to give to their partners, as a means of identifying partners who came to the health department as having been referred by that subject.

In the patient-referral group, the subjects initially had full responsibility for the notification of partners. They were asked to locate partners and give them coded cards and to request that partners come in for counseling, testing, or both within one month. The counselors reviewed the various ways to talk to partners about HIV exposure and discussed difficulties in notifying partners. At the end of one month, the counselors attempted to locate all partners who had not come to the health department, in order to determine whether they were aware of their exposure to HIV.

\section{Data Collected}

Limited data on sociodemographic characteristics and risk factors were available in the routine reports of pretest counseling sessions for all persons being tested for HIV. The data on partners included information provided by the subject about the partner and the sexual or needle-sharing behavior, and information assessed in counseling sessions with located partners about risk factors, awareness of HIV exposure, serologic status (if tested), the receipt of coded cards, and the acceptability of the partner-notification method.

\section{Statistical Analysis}

The subjects, those who declined to participate, and those who were ineligible or unavailable for the study were compared in terms of base-line demographic and risk-factor variables by means of chisquare tests for categorical variables and analysis of variance for continuous variables. The same methods were used to compare subjects in the two study groups to verify the success of the randomization procedure.

For analyses concerning partners, the methods of analysis accounted for the subject as the unit of randomization through ratio estimates and their corresponding covariance structure. ${ }^{28}$ The numerators of these ratios were the averages among subjects of the sums of variables for the partners of each subject, and the denominators were averages among subjects of the number of partners for each subject. The covariance structure for these ratio estimates accounts for the correlation among partners of the same subject and is determined on the basis of the variability among subjects of their respective contribution to the numerators and denominators by Taylor series linearization methods..$^{29}$ By means of chi-square tests based on these ratio estimates relative to the corresponding covariance structure, partners with known notification status and those with unknown status were compared in terms of major variables. ${ }^{30}$ In addition, the two study groups were compared in terms of baseline demographic and risk-factor variables and efficacy variables. The ratio estimates assessed for efficacy included the following variables: the proportion of partners notified and whether they could be located, their HIV status, and their previous awareness of exposure.

\section{RESULTS}

During the study period, 534 persons had HIV tests at the three health departments. Nearly half were not available for study because they did not return 
for counseling after the test and could not be located $(n=247)$ or were counseled outside the study $(n=8)$. An additional 22 percent of HIV-positive clients were ineligible for various reasons. Of the 162 clients both available and eligible, 74 (46 percent) agreed to participate and 88 (54 percent) declined (Table 1).

\section{Characteristics of Participants}

Study participants were more likely to be female (31 percent) and black (87 percent) than those who declined to participate, were ineligible, or were unavailable for study (Table 2). These differences were due to higher rates of refusal among males and whites and to the higher rates of ineligibility among whites. Study subjects and persons not available for study were slightly younger (mean age, 30 and 29 years, respectively) than those who declined or were ineligible (mean age, 32 and 33 years). Male participants were more likely to be homosexual or bisexual, especially as compared with those who were not available (76 percent vs. 47 percent). The frequency of use of intravenous drugs was similar in the various groups. Study subjects were somewhat more likely to have been tested confidentially (rather than anonymously) than persons in the other groups.

Information available only for study subjects showed that 12 percent had a partner known to be HIV-infected, 18 percent reported having sex with a prostitute, 19 percent had been paid for sex, and 81 percent had three or more heterosexual partners. Fifty-eight percent had visited the health departments' sexually transmitted-disease clinics in the previous year; 63 percent had been treated previously for gonorrhea, and 42 percent for syphilis. Of the 74 study subjects, 39 were randomly assigned to the provider-referral group and 35 to the patient-referral group. Subjects in both groups had similar numbers of reported partners (median, 4 per index patient; mean, 4.2).

\section{Characteristics of Partners}

Of the 310 partners reported by the 74 participants, over three quarters were male. One third had shared needles with a subject; two thirds were sex partners only. A total of 128 of the 310 partners (41 percent) were known to have been notified (through the location of partners by counselors or by partners' appearing at the health department): 78 (50 percent) in the provider-referral group and 50 (33 percent) in the patient-referral group (Table 3 ). Partners who were definitely notified of their exposure to HIV were more likely than those whose status was unknown (i.e., who were not definitely notified) to be black ( 89 percent vs. 79 percent, $\mathrm{P}=0.07$ ); of the men, those known to have been notified were somewhat more likely to be homosexual or bisexual (48 percent vs. 39 percent, $\mathrm{P}=0.22$ ). Sex, median age, and risk factors for HIV infection were not significantly related to notification status. Whether a partner could be located was largely

\begin{tabular}{lr} 
Table 1. Enrollment of Subjects in the North \\
Carolina HIV Partner-Notification Study, No- \\
vember 16, 1988, through June 30, 1990. \\
\hline \hline CATEGory & No. \\
HIV-positive persons tested at Durham, & 534 \\
Mecklenburg, and Wake county & \\
health departments & \\
Not available for study & 255 \\
Did not return for results & 247 \\
Counseled outside the study & 8 \\
Ineligible & 117 \\
Repeat positive test & 22 \\
All partners anonymous & 8 \\
No partners in past year & 62 \\
Patients or partners geographically & 25 \\
distant & 162 \\
Eligible for study & 88 \\
Declined & 74 \\
Enrolled & \\
\hline
\end{tabular}

a function of whether the index patient provided a name or address or only a description.

\section{Efficacy of Provider Referral}

In the provider-referral group, the public health counselor and the subjects notified a total of 78 of the 157 partners (50 percent) (Table 4). Thirty-six partners accepted HIV testing. Nine were seropositive and 27 were seronegative. In contrast, in the patient-referral group, only 10 of 153 partners ( 7 percent) were notified by the subject ( 8 came into the health department on their own, and 2 did not but were subsequently followed up by the counselors). Seven reported receiving a coded card from a study subject. Five of the 10 partners in this group accepted HIV testing. One was seropositive and four were seronegative. There were 42 partners of subjects in the patient-referral group who did not come to the health department on their own and whom the public health counselor was able to locate. Of these, 20 accepted HIV testing. Four were seropositive, for a total of 25 partners tested for the patient-referral group. Of the 61 partners

Table 2. Characteristics of Study Subjects and HIV-Positive Persons Who Did Not Participate in the Study.*

\begin{tabular}{|c|c|c|c|c|c|c|}
\hline Characteristic & $\begin{array}{l}\text { SUBJECTS } \\
(N=74)\end{array}$ & $\begin{array}{l}\text { DECLINED } \\
(\mathrm{N}=88)\end{array}$ & $\begin{array}{r}\text { INELIGIBLE } \\
(\mathrm{N}=117) \\
\text { number }\end{array}$ & $\begin{array}{c}\text { Not } \\
\text { Avallable } \\
(\mathrm{N}=255) \\
\text { (percent) }\end{array}$ & $\begin{array}{c}\text { Total } \\
(\mathrm{N}=534)\end{array}$ & P Value \\
\hline Female sex & $23(31)$ & $13(15)$ & $21(18)$ & $47(20)$ & $104(20)$ & 0.057 \\
\hline Black race & $64(87)$ & $52(59)$ & $58(50)$ & $158(64)$ & $332(63)$ & $<0.001$ \\
\hline $\begin{array}{l}\text { Homosexuality or } \\
\text { bisexuality }{ }^{\dagger}\end{array}$ & $37(76)$ & $47(67)$ & $68(71)$ & $94(47)$ & $246(59)$ & 0.007 \\
\hline $\begin{array}{l}\text { Intravenous } \\
\text { drug use }\end{array}$ & $26(35)$ & $26(31)$ & $30(27)$ & $79(31)$ & $161(31)$ & 0.65 \\
\hline $\begin{array}{c}\text { Confidential } \\
\text { testing } \neq\end{array}$ & $29(53)$ & $26(36)$ & $32(33)$ & $98(40)$ & $185(40)$ & 0.11 \\
\hline
\end{tabular}

*Percentages shown are of those for whom data were available: for homosexuality or bisexuality, $n=414$ (49 for the subjects and 365 for the nonparticipants); for testing method, $n=465$ ( 55 for the subjects and 410 for the nonparticipants). $P$ values are for the comparison between subjects and nonparticipants.

tPercentage of men.

$\ddagger$ Testing was either confidential or anonymous. 
Table 3. Characteristics of Partners in the North Carolina HIV Partner-Notification Study.

\begin{tabular}{|c|c|c|c|}
\hline \multirow[t]{2}{*}{ Characteristic } & \multicolumn{2}{|c|}{ Notification Status* } & \multirow[t]{2}{*}{ P VALue $\dagger$} \\
\hline & $\begin{array}{l}\text { KNOWN } \\
(\mathrm{N}=128)\end{array}$ & $\begin{array}{l}\text { UNKNOWN } \\
(\mathrm{N}=182)\end{array}$ & \\
\hline Black race - no. $(\%)$ & $108(89)$ & $131(79)$ & 0.07 \\
\hline Male sex - no. (\%) & $97(76)$ & $141(78)$ & 0.81 \\
\hline Age (median - yr) & 32 & 31 & 0.78 \\
\hline $\begin{array}{l}\text { Homosexuality or bisexu- } \\
\text { ality }- \text { no. }(\%) \ddagger\end{array}$ & $43(48)$ & $52(39)$ & 0.22 \\
\hline $\begin{array}{l}\text { Needle-sharing partner - } \\
\text { no. }(\%)\end{array}$ & $42(34)$ & $63(37)$ & 0.61 \\
\hline $\begin{array}{l}\text { Never used condoms - } \\
\text { no. }(\%)\end{array}$ & $69(73)$ & $96(77)$ & 0.48 \\
\hline \multicolumn{4}{|l|}{ Study group } \\
\hline Provider referral & $78(50)$ & $79(50)$ & 0.01 \\
\hline Patient referral & $50(33)$ & $103(67)$ & \\
\hline \multicolumn{4}{|c|}{$\begin{array}{l}\text { *"Known" indicates that the partners had definitely been notified of their } \\
\text { exposure to HIV, and "Unknown" that we could not be sure whether they } \\
\text { had been notified. Percentages refer to numbers of partners for whom data } \\
\text { were available. }\end{array}$} \\
\hline $\begin{array}{l}\text { †Adjusted for the clustering } \\
\text { ‡Only men are included. }\end{array}$ & & & \\
\hline
\end{tabular}

of subjects in both groups who were tested, 14 (23 percent) were HIV-positive. Only 7 (6 percent) of the 112 partners of subjects in both study groups who were located by the public health counselors were already aware of their exposure to HIV; there was no significant difference between the study groups in this variable.

\section{Discussion}

North Carolina's Communicable Disease Control Law requires all HIV-positive persons to contact their partners, either themselves or through a counselor employed by the state. Violation of this law is a misdemeanor punishable by a fine, a prison term, or both. In spite of this law, the patient-referral method, with subjects responsible for notifying their partners, was quite ineffective in this study; only 7 percent of the partners were notified by subjects in the patient-referral group. The provider-referral method, with the

Table 4. Efficacy of Referral Methods in the North Carolina HIV Partner-Notification Study.

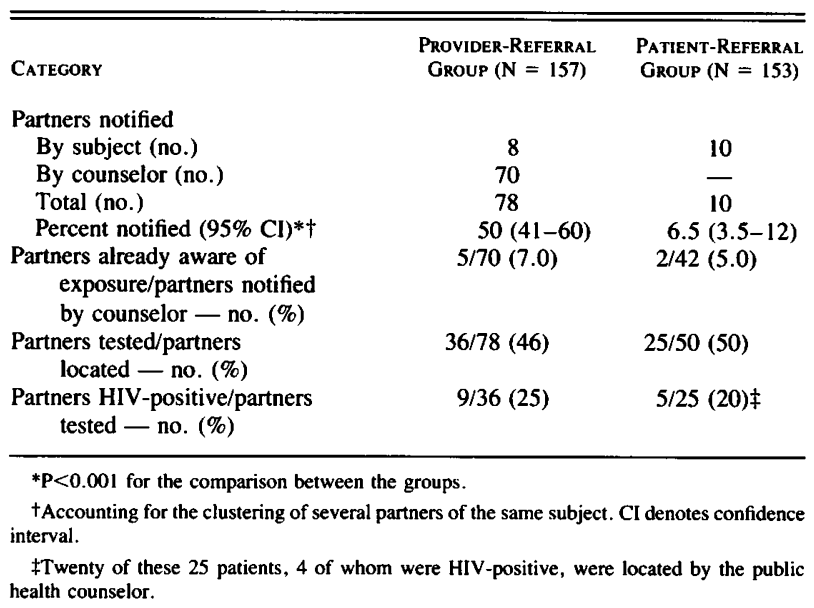

public health counselors attempting to notify partners with a participant's consent or after a two-week interval, reached 50 percent of the partners in that group. Almost half the notified partners accepted HIV testing, and about one fourth of these tested positive for HIV.

The higher rate of location and notification of partners by the provider-referral method could have important implications. Partners who are HIV-positive might have their lives prolonged by earlier therapy, and partners who are HIV-negative might avoid the infection entirely by modifying their sexual behavior. In our study, the number of HIV-negative partners notified by providers was more than six times greater than the number notified by the subjects alone. Only a small fraction of these patients already knew they might have been exposed to HIV.

Because partners notified by participants may have elected not to come to the health department, counselors attempted to reach all the partners to determine whether they had been notified. In both study groups, however, notification status could not be determined for partners who could not be located. If we conservatively assume that in the patient-referral group the proportion of partners who were notified and did not come to the health department was twice as high for the partners the counselors could not locate as for the partners they could locate $(2 \times[2 / 42]=10$ percent), then the overall number of partners notified by subjects would be $20(8+2+[0.10(153-50)])$, or about 13 percent - still much lower than in the provider-referral group.

\section{Limitations of the Study}

If the study subjects agreed to participate only because they wanted help in notifying their partners, then those randomly assigned to the patient-referral group would be unlikely to notify their own partners; this was indeed the case. Potential subjects who declined may have done so partly because they planned to notify their own partners. If all those who declined $(n=88)$ had agreed to participate and had the same number of partners as the participants $(88 \times 4.2$ partners per subject $=370$ partners, so that 185 more partners were notified in each study group), even under the extreme assumption that those who declined notified all their partners themselves, the proportion of partners notified in the providerreferral group would have been substantially greater $([78+185] /[157+185]=77$ percent $)$ than that in the patient-referral arm $([10+185] /[153+185]=$ 58 percent).

Our subjects were predominantly black male homosexuals or bisexuals from a state with a moderate prevalence of the acquired immunodeficiency syndrome. Forty-two percent of the subjects reported previous treatment for syphilis and presumably had some experience with contact tracing. The subjects may have felt more comfortable with the use of public health counselors than the potential subjects who declined to 
participate or other groups of HIV-positive persons. Our results may therefore be less applicable to groups with no previous experience with local health departments.

\section{Barriers to the Effectiveness of Provider Referral}

Forty-six percent of the HIV-positive persons tested at the three health departments did not return for their test results or post-test counseling - between the percentage in North Carolina as a whole (42 percent) and that in the United States during 1989 (51 percent) (Dillon B, Centers for Disease Control: personal communication). In our study 90 (35 percent) of 255 clients who were not available for study had been previously tested for HIV; 52 percent were positive and 48 percent were negative or had indeterminate results. Previously tested persons may feel less inclined to return for their test results than those not previously tested. The change from anonymous testing to confidential testing, which had recently been planned for North Carolina, may increase the number of infected persons who receive their test results and the number for whom partners could be notified by provider referral. It is possible, however, that a decrease in testing and an increase in the use of false names and addresses may result instead. In Oregon the demand for HIV testing increased by 50 percent overall and by 125 percent among gay men when anonymous testing was made available. ${ }^{31}$

In spite of our counselors' efforts, 50 percent of the partners of subjects in the provider-referral group could not be notified because of limited or incorrect information provided by subjects. Partners who could not be located may have been truly anonymous or transient partners, or they may not have been located because of the subjects' unwillingness to give correct information. The number of anonymous partners, both sex partners and needle-sharing partners, is large and has reportedly increased for patients with syphilis. ${ }^{32-34}$ Much of the increase in sexual contact with anonymous partners appears to be related to the exchange of sex for drugs or for money to buy drugs.

Among the eligible subjects, 54 percent declined participation, which would have required them to disclose the names of their partners and information on how to locate them. Those who declined cited the shock of finding that they were HIV-positive and their concern about discrimination and loss of confidentiality for the partners. ${ }^{35}$ Moreover, participation in our study did not guarantee entry into drug trials or continuing medical care, factors that often encourage participation by $\mathrm{HIV}$-infected patients in research studies.

\section{Suggestions for Locating Partners of HIV-Infected Persons}

Training index patients to communicate more effectively with their partners about HIV exposure may be helpful, but it may have limited usefulness. Up to 27 percent of HIV-positive persons identified at the Alameda County Alternate Testing Site did not plan to tell their primary or nonprimary sex partners about their HIV status, ${ }^{36}$ and 52 percent of infected men in Los Angeles reported that they kept their infection secret from one or more sex partners. ${ }^{37}$ Our study counselors provided participants with detailed descriptions of various ways to talk with partners and used role playing to simulate some uncomfortable situations that might arise. Even so, many subjects in the patient-referral group adamantly refused to locate any of their partners, and subjects in the providerreferral group requested that two thirds of their partners be located by study counselors.

Efforts to reduce the number of anonymous sex partners and needle-sharing partners through an increase in the number of comprehensive drug-treatment programs and the enactment of strict antidiscrimination and confidentiality laws to encourage more index patients to provide the names of partners could help to make the provider-referral method of notifying partners more effective. ${ }^{35,38}$ The development of focused educational programs for groups of people at high risk for HIV infection is a possible alternative to the notification of individual partners. ${ }^{9,20,38,39}$

We are indebted to our research staff, Jennifer Mahnke, C.Y. Shen, Monique Stephens, and Brian Rice; to our public health counselors, Stacey Anderegg, Cheri Britton, and Belinda Long; and to the staffs of the Durham, Mecklenburg, and Wake County, North Carolina, health departments.

\section{ReFERENCES}

1. Toomey K, Cahill K, Cates W. Partner notification for HIV prevention: current state programs and policies in the United States. Presented at the Fifth International Conference on AIDS, Montreal, June 4-9, 1989. abstract.

2. Toomey KE, Cates W. Partner notification for the prevention of HIV infection. AIDS 1989;3:Suppl 1:S57-S62.

3. Rothenberg RB, Potterat JJ. Strategies for management of sex partners. In: Holmes KK, Mardh PA, Sparling PF, Wiesner PJ, eds. Sexually transmitted diseases. 2nd ed. New York: McGraw-Hill, 1990:1081-6.

4. Brandt AM. No magic bullet: a social history of venereal disease in the United States since 1880. New York: Oxford University Press, 1987.

5. Partner notification for preventing human immunodeficiency virus (HIV) infection - Colorado, Idaho, South Carolina, Virginia. MMWR 1988;37: 393-6, 401-2.

6. Association of State and Territorial Health Officials, National Association of County Health Officials, U.S. Conference of Local Health Officers. Guide to public health practice: HIV partner notification strategies. Washington, D.C.: Public Health Foundation, 1988.

7. World Health Organization. Global programme on AIDS and programme of STD. J AIDS 1989;2:248-55.

8. Idem. Consensus statements on HIV transmission. Lancet 1989;1:396.

9. Judson FN. Partner notification for HIV control. Hosp Pract [Off] 1990; 25(12):63-73.

10. Dunlop EMC, Lamb AM, King DM. Improved tracing of contacts of heterosexual men with gonorrhea: relationship of altered female to male ratios. Br J Vener Dis 1971;47:192-5.

11. Woodhouse DE, Potterat JJ, Muth JB, Pratts CI, Rothenberg RB, Fogle JS A civilian-military partnership to reduce the incidence of gonorrhea. Public Health Rep 1985;100:61-5.

12. Phillips L, Potterat JJ, Rothenberg RB, Pratts C, King RD. Focused interviewing in gonorrhea control. Am J Public Health 1980;70:705-8.

13. Henderson RH. Control of sexually transmitted disease in the United States - a federal perspective. Br J Vener Dis 1977;53:211-5.

14. Faruki H, Kohmescher R, McKinney WP, Sparling PF. A community-based outbreak of infection with penicillin-resistant Neisseria gonorrhoeae not producing penicillinase (chromosomally mediated resistance). N Engl J Med 1985;313:607-11.

15. Landis SE, Earp JA, Koch GG. Impact of HIV testing and counseling on subsequent sexual behavior in a rural southern state. AIDS Educ Prev (in press). 
16. St Lawrence JS, Hood HV, Brasfield T, Kelly JA. Differences in gay men's AIDS risk knowledge and behavior patterns in high and low AIDS prevalence cities. Public Health Rep 1989;104:391-5.

17. Petersen H, Padian N, Glass S, Moreno A, Ajaniku I, Wofsy C. Behavior modification in couples enrolled in a study of heterosexual transmission. Presented at the Fifth International Conference on AIDS, Montreal, June 4-9, 1989. abstract.

18. Cates W Jr, Handsfield HH. HIV counseling and testing: does it work? Am J Public Health 1988;78:1533-4.

19. Higgins DL, Galavotti C, O'Reilly KR, et al. Evidence for the effects of HIV antibody counseling and testing on risk behaviors. JAMA 1991;266: 2419-29.

20. Toomey KE. Efficacy and evaluation of partner notification. Presented a the Fifth International Conference on AIDS, Montreal, June 4-9, 1989. abstract.

21. Clumeck N, Taelman H, Hermans P, Piot P, Schoumacher M, De Wit S. A cluster of HIV infection among heterosexual people without apparent risk factors. N Engl J Med 1989;321:1460-2.

22. Wykoff RF, Heath $\mathrm{CW} \mathrm{Jr}$, Hollis SL, et al. Contact tracing to identify human immunodeficiency virus infection in a rural community. JAMA 1988;259:3563-6.

23. Giesecke J. Combatting AIDS with contact tracing: the Swedish Study Group on contact tracing for HIV infection. Presented at the Fifth International Conference on AIDS, Montreal, June 4-9, 1989. abstract.

24. Ramstedt K, Hallhagen G, Lundin BI, et al. Contact tracing for human immunodeficiency virus (HIV) infection. Sex Transm Dis 1990;17:3741.

25. Guadalupe R, Avila C, Herrera E, Hernandez M, Sepulveda J. The impact of partner notification on sexual behavior among a heterosexual population. Presented at the Sixth International Conference on AIDS, San Francisco, June 20-24, 1990. abstract.
26. Jones B, Wroten J, Sims J, et al. HIV partner notification in Florida. In Final program and abstracts, Sixth International Conference on AIDS, San Francisco, June 20-24, 1990. Vol. 3. San Francisco: University of California, 1990:253. abstract.

27. Centers for Disease Control. HIV/AIDS Surveillance Report. August 1991

28. Cochran WG. Sampling techniques. 3rd ed. New York: John Wiley, 1977.

29. Woodruff RS. A simple method for approximating the variance of a complicated estimate. J Am Stat Assoc 1971;66:411-4.

30. Koch GG, Freeman DH, Freeman JL. Strategies in the multivariate analysis of data from complex surveys. Intern Stat Rev 1975;43:59-78.

31. Fehrs LJ, Fleming D, Foster LR, et al. Trial of anonymous versus confidential human immunodeficiency virus testing. Lancet 1988;2:379-82.

32. Andrus JK, Fleming DW, Harger DR, et al. Partner notification: can it control epidemic syphilis? Ann Intern Med 1990;112:539-43.

33. Brandt AM. Sexually transmitted disease: shadow on the land, revisited. Ann Intern Med 1990;112:481-3.

34. Alternative case-finding methods in a crack-related syphilis epidemic Philadelphia. MMWR 1991;40:77-80.

35. Angell M. A dual approach to the AIDS epidemic. N Engl J Med 1991; 324:1498-500.

36. Kegeles SM, Catania JA, Coates TJ. Intentions to communicate positive HIV-antibody status to sex partners. JAMA 1988;259:216-7.

37. Marks G, Richardson JL, Maldonado N. Self-disclosure of HIV infection to sexual partners. Am J Public Health 1991;81:1321-3.

38. Cates W Jr, Bowen GS. Education for AIDS prevention: not our only voluntary weapon. Am J Public Health 1989;79:871-4.

39. Woodhouse D, Potterat J, Klovdahl A, Darrow W, Muth S, Muth J. Socia networks in the transmission of HIV infection. In: Final program and abstracts, Sixth International Conference on AIDS, San Francisco, June 20-24, 1990. Vol. 3. San Francisco: University of California, 1990:258. abstract. 